\title{
RADICAL CYCLIZATION REACTIONS. CYCLOPROPANE RING FORMATION BY 3-EXO-CYCLIZATION OF 5-PHENYLTHIO-3-PENTENYL RADICALS
}

\author{
Živorad Čeković ${ }^{*}$ and Radomir Saičić \\ Department of Chemistry, Faculty of Science, University of Belgrade, Studentski trg 16, \\ P. O. Bux 550, 11001 Belgrade, and Institute for Chemistry, Technology and Mctallurgy, \\ Belgrade, Yugoslavia
}

Abstract: Free radical cyclopropane ring closure was accomplished by thermal decomposition of thiohydroxamic esters of 6-phenylthio-4-hexencic acids. When the reaction was ferformed in the presence of acrylonitrile, an addition/cyclization/elimination process took place and the corresponding cyclopentanecarbonitriles were obtained.

Free redical formation of cyclopropane ring was rether considered a a 3-butenyl/cyclopropylcarbinyl radical interconversion than as a method for the construction of a three membered carbocyclic ring:-4 cyclopropylcarbinyl radicals were observed as intermediates in 1,2-group migration and are usually in equilibrium with 3-butenyl type radicals. ${ }^{2,3,5-8}$ cyclopropane derivatives were only prepared, under homolytic conditions, by a free racical displacement in 3-butenylcobaloximes by halomethyl radicals. 9

We assumed that 3-exc-cyclization of 3-pentenyl radicals 1 to the cyclopropane derivatives $\underline{3}$ could be achieved by an efficient quenching of the cyclopropylcarbinyl radicals $\frac{2}{2}$. In order to favour 3-exo-cyclization ( $k_{c}=$ $0.8-1.3 \times 10^{4} \mathrm{sec}^{-1}$ at $\left.25^{\circ} \mathrm{C}\right)^{10}$ and suppress reversible opening of the cyclopropylcarbinyl radical $2\left(k_{f}=1.3 \times 10^{8} \mathrm{sec}^{-1}\right.$ at $\left.25^{\circ} \mathrm{C}\right),{ }^{11}$ it was necessary to find a reaction for quenching radicals $\underline{2}$ having a rate constant higher than ring opening $\left(k_{q}>k_{f}\right)$. Since it was estimated that the rate of elimination of the phenylthio group ( $k_{e}$ ) adjacent to a radical certer would be higher than $>1.6 \times 10^{7} \mathrm{sec}^{-1}$ at $25^{\circ} \mathrm{C},{ }^{12}$ we wanted to check if this elimination could be a gcod propagation step in the radical chain reaction and afford cyclopropane 3 as final reaction product.

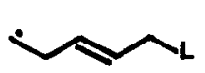

$\underline{1}$

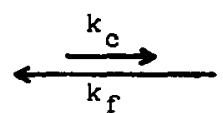

Free radica

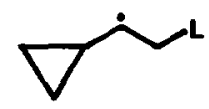

$\underline{2}$
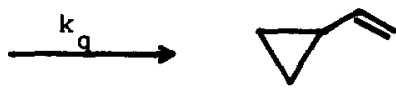

$\underline{3}$

tenyl type radicals 2 possessed a prenylthio group, as a good radical lea- 
ving group, in the 5-position. Thus, by thermal deccmposition of thiohydroxamic esters of 6-phenylthio-4-hexenoic acids 4 , in boiling toluene solition, 2-vinylcyclopropane derivatives $\underline{5}$ were obtained in $43-60 \%$ yields (Method A, Scheme 1.1.3 on the other hand, 3-pentenyl type radicals 1 could be intercepted, before cyclopropane ring closure, by an intermolecular addition to the radicophilic olefins, thus generating 5-heptenyl type radicals. By decomposition of esters 4 under the same experimental conditions as in Method A, but in the presence of a five-fold excess of acrylonitrile, cyclopentanecarbonitriles 6 were obtained in $50-65 \%$ yields (Method B) (see Scheme 1. and Table 1.). 15

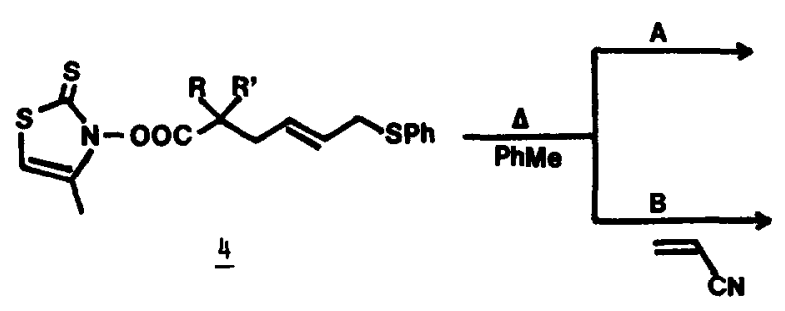

Scheme 1

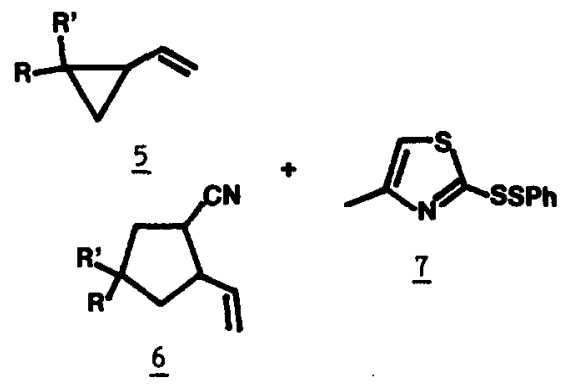

By performing the decomposition of esters 4 without electron deficient olefins the intermeaiary 5-phenylthio-3-pentenyl radicals 8 (Scheme 2. ) underwent intramolecular 3-exo-cyclization with concomitant expulsion of the

Table 1. Decomposition of thiohydroxamic esters of 6-phenylthio-4-hexenoic $\operatorname{ac} 1 \mathrm{ds} \underline{4}$

\begin{tabular}{cccccc}
\hline $\begin{array}{l}\text { Starting } \\
\text { esters }\end{array}$ & $\mathrm{R}$ & $\mathrm{R}^{-}$ & Method & Products & $\begin{array}{c}\text { Isolated and } \mathrm{GC}^{\mathrm{C}} \\
\text { yields in } \%\end{array}$ \\
\hline$\frac{4 a}{4 a}$ & $\mathrm{PhCH}_{2}$ & $\mathrm{H}$ & $\mathrm{A}$ & $\underline{5 a}$ & $32(47)$ \\
$\frac{4 b}{4 b}$ & $\mathrm{PhCH}_{2}$ & $\mathrm{H}$ & $\mathrm{B}$ & $\underline{6 a}$ & $33(50)^{\mathrm{d}}$ \\
$\frac{4 \mathrm{~b}}{4 \mathrm{c}}$ & $\mathrm{PhCH}_{2}$ & $\mathrm{CH}_{3}$ & $\mathrm{~A}$ & $\underline{5 b}$ & $25(43)$ \\
$\underline{4 c}$ & $\mathrm{PhCH}_{2}$ & $\mathrm{CH}_{3}$ & $\mathrm{~B}$ & $\underline{6 b}$ & $40(52)$ \\
\hline
\end{tabular}

Method A: Thermal decomposition of 4 in refluxing toluene.

Method B: Thermal decomposition of $\underline{4}$ in refluxing tcluene in the presence of excess of acrylonitrile.

a) Prepared according to the Barton procedure (ref. 16).

b) Reaction products were isolated on silica gel column, using petroleumether/acetone 99 : 1 as eluent and characterized by IR, NMR and mass spectra.

c) Yields of reaction products were also determined by GC.

d) Taken from reference 17 . 
phenylthio radical, thus forming a cyclopropane ring 5 . The yields of cyclopropane derivatives $\underline{5}$ did not charge appreclably whether primary, secondary or tertiary 5-phenylthio-3-pentenyl radicals 8 were involved as intermediates, thus indicating that the intramolecular reaction leading to the cyclopropane ring does not depend on the nucleophilicity of the radical species, but depends on the appropriate conformation of the intermediary radicals $\underline{8}$, and is supported by the presence of the phonylthio group in the sliylie position. Since the rate of 3-exo-cyclization $\left(k_{c}\right)$ of 3-pentenyl type radi-

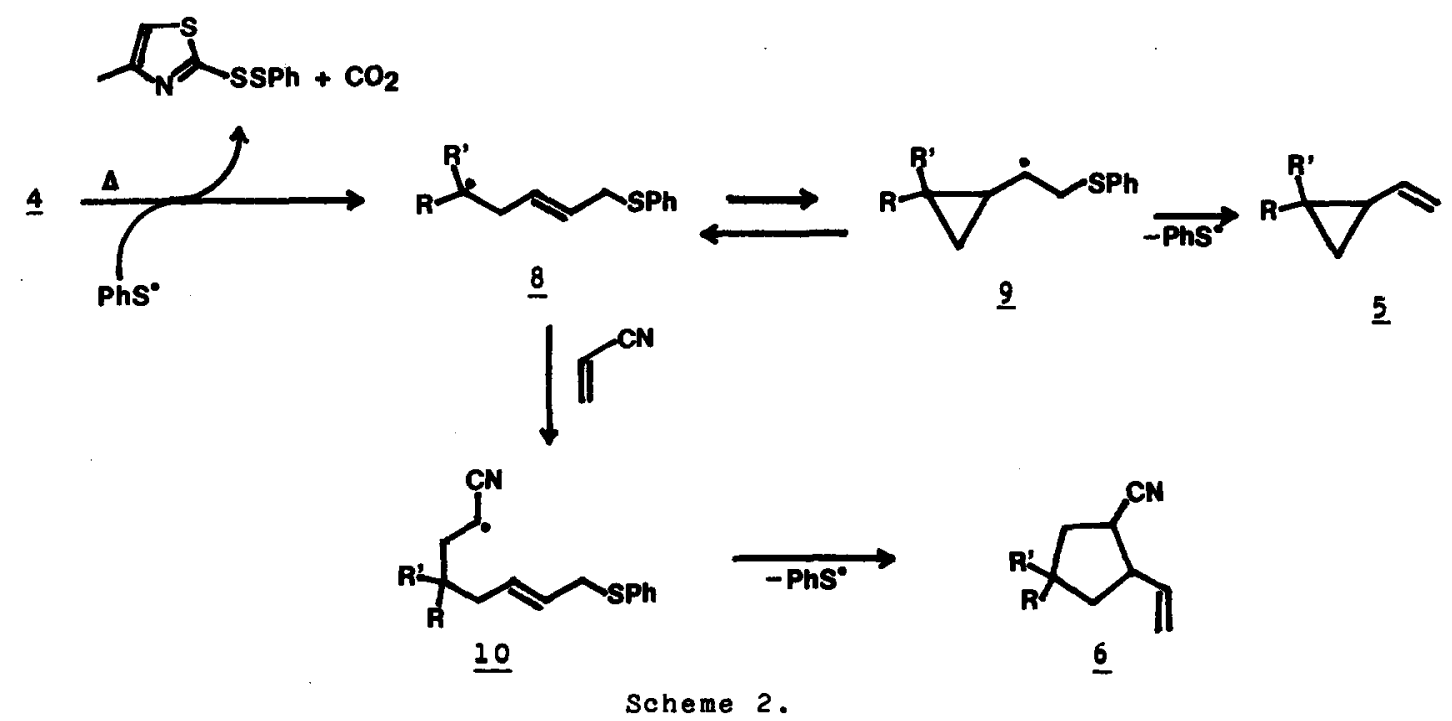

cals $\underline{8}$ is wuch lower than the rate of ring opening $\left(k_{f}\right)$ of the cyclcpropylcarbinyl radicals 9 , we believe that the competing reversible reaction could takes place before expulsion of the phenylthio radical, and that for this reasons the yields of cyclopropane derivatives $\underline{5}$ were not high. Newcomb's resulti on the 4-exo-cyclizations of 2,2-dimethyl-5-cyano-4-pentenyl radicals, which appeared during the preparation of the present paper, support our findings concerning the 3-exo-cyclizstions. 18

In addition to the radical 3-exo-cyclizations, 2-vinylcyclopropane derivatives were obtained from similar precursors, involving an intramolecular addition of carbanion intermediates and concerted elimination of a leaving group. 19

However, the intramolecilar addition reaction of radicals $\underline{8}$, leading to the vinylcyclopropanes $\underline{5}$, was completely suppressed when the reactions were performed in the presence of excess of acrylonitrile (Methcd B). By using a five-fold of excess of the radicophilic olefins, the rate of intermolecular addition of 5-phenylthio-3-pentenyl radicals 8 to these olefins was higher than the rate of 3-exo-cyclization, and therefore the formation of 5-heptenyl type radicals 10 by intermolecular addition to the radicophilic olefins 
and their subsequent cyclization to 2-vinylcyclopentanecarboritriles 6 was described in our previous paper! 7 By decomposition of esters 4 , according to Method $B$, in addition to vinylcyclopentanecarbonitrile 6a, 2-vinylcyclopropane derivatives 5 a were obtained in $3 \%$ yield.

\section{REFERENCES}

1. J. W. Wilt, in Eree Radicals, Vol. 1. Ed. by J. K. Kochi, John Wiley, New York, 1972 , Chapter 8 .

J.-M. Surzur, in Reactive Intermediates, Vol. 2. Ed. by R. Abramovich, Plenum Press, New York, 1982, Chapter 3 .

2. L. K. Montgomery and J.W. Matt, J. Am. Chem. Soc., 89, 3050 (1967).

3. T. A. Halgren, M. E. H. Howden, M. E. Medof and J. D. Roberts, J. Am. Chem. Soc., 89, 3051 (1967).

4. P. C. Wong and D. Griller, J. Org. Chem., 46, 2327 (1981).

5. P. Dowd and S. - Ch. Choi, J.Am. Chem. Soc., 109, 3493 (1987); Tetrahedron, $45,77(1989)$.

6. A. L. J. Beckwith and D. M. O'Shea, Tetrahedron Letters, 27, 4525 (1986).

7. G. Stork and R. Mook, Jr., Tetrahedron Letters, 27, 4529 (1986).

8. B. Giese, N. Heinrich, H. Horler, W. Koch, H. Schwarz, Chem. Ber., 119, $3528(1986)$.

9. A. Bury, S. T. Corker, M. D. Johnson, J. Chem. Soc., Perkin Trans., I, $645(1982)$.

10. A. Effio, D. Griller, K. U. Ingold, A. L. J. Beckwith and A. K. Serelis, J.Am. Chem. Soc., 102, 1734 (1980); C. Chatgiliologu, K. U. Ingold, J. C. Scaiano, J.Am. Them. Soc., 103, 7739 (1981); L. J. Johnston, J. Lusztyk, D. D. M. Wayner, A. N. Abeywickreyma, A. L. J. Beckwith, J. C. Scaiano and $\mathrm{K}$. U. Ingold, J.Am. Chem. Soc., 107, 4594 (1986).

11. B. Maillard, D. Forrest and K. U. Ingold, J. Am. Chem. Soc., 98, 7024 (1976).

12. T. E. Booth, J. L. Greene, Jr., and P. B. Sheviln, J. Am. Chem. Soc., 98, $951(1976)$.

13. Typical experimental procedure. Method A. Thiohydroxamic esters 4 were prepared insitu without isolation (ref. 16.). To the mixture of 0.878 ( $5.9 \mathrm{mM})$ of $\mathrm{N}-\mathrm{hyd}$ roxy-4-methylthiazole-2(3H)-thione, $0.062 \mathrm{~g}(0.3 \mathrm{mM})$ of dimethylaminopyridine and $0.47 \mathrm{~g}(6 \mathrm{mM})$ of pyridine in ether ( $30 \mathrm{ml})$, a solution of acyl chloride ( $5.7 \mathrm{mM}$ ) was slowly added. When the reaction was completed $(l \mathrm{~h})$, the solvent was removed and the esters were used without purification. The oily residue containing ester 4 (about $5.6 \mathrm{mM}$ ) was dissolved in toluene $(20 \mathrm{ml})$ and added dropwise to stirred refluxing toluene $(30 \mathrm{ml})$, in an inert atmosphere. After the addition was completed, the reaction mixture was heated to reflux during 45 min. The solvent was then removed under reduced pressure and the crude reaction products were purified by chromatography on silica gel column (petroleumether/acetone 99 : 1$)$. 2-Benzylvinylcyclopropane 5 a was isolated $(0.298$, $32 \%$ yield) as a colorless oil. IR (neat): $3060,302 \overline{0,} 2920,2840,1640,1605,1495$, $1480,1465,1440,1030,740,700 \mathrm{~cm}^{-1} \cdot{ }_{\mathrm{H}-\mathrm{NMR}}(\mathrm{s}): 0.50-0.70$ (m, $\left.2 \mathrm{H}\right)$, $0.75-1.50(\mathrm{~m}, 2 \mathrm{H}), 2.50-2.65(\mathrm{~m}, 2 \mathrm{H}), 4.70-5.60(\mathrm{~m}, 3 \mathrm{H}), 7.20(\mathrm{~s}, 5 \mathrm{H})$. MS : $158\left(\mathrm{M}^{+}\right) 143,129,115,104,91(100 \%), 79,65,51$.

Method B. Reaction of thiohydroxamic esters 4 with a five molar excess of acrylonitrile in toluene solution, were performed under the same experimental conditions as applied in Method A. See also reference 14 and 17.

14. R. N. Saičić, and Ž. Čeković, Tetrahedron, 46, 3627 (1990).

15. Ž. Čeković and R. N. Saičić, Tetrahedron Letters, 27, 5893 (1986).

16. D. H. R. Barton, D. Bridon, I. Fernandez-Picot, and S. Z. Zard, Tetrahedron, 43, $2733(1987)$; D. H. R. Barton, D. Bridon and S. 2. Zard, Tetrahedron, 43,5307 (1987).

17. R.N. Saíić and Ž. Čeković; Tetrahedron Letters, 31, 4203 (1990).

18. S. -U. Park, T. R. Varick and M. Newcomb, Tetrahedron Letters, 31 , 2975 (1990).

19. R. Matović, R. N. Saičić and Ž. Čeković, unpublished results. 